\title{
Changing remuneration systems: effects on activity in general practice
}

Allan Krasnik, Peter P Groenewegen, Poul A Pedersen, Peter v Scholten, Gavin Mooney, Adam Gottschau, Henk A Flierman, Mogens T Damsgaard

\begin{abstract}
Objective-To investigate the effects on general practitioners' activities of a change in their remuneration from a capitation based system to a mixed fee per item and capitation based system.

Design-Follow up study with data collected from contact sheets completed by general practitioners in one period before (March 1987) a change in their remuneration system and two periods after (March 1988, November 1988), with a control group of general practitioners with a mixed fee per item and capitation based system throughout.
\end{abstract}

Setting-General practices in Copenhagen city (index group) and Copenhagen county (control group).

Subjects-265 General practitioners in Copenhagen city, of whom 100 were selected randomly from the 130 who agreed to participate (10 exclusions) and 326 general practitioners in Copenhagen county.

Main outcome measures-Number of consultations (face to face and by telephone) and renewals of prescriptions, diagnostic and curative services, and specialist and hospital referrals per 1000 enlisted patients in one week.

Results-Of the 75 general practitioners who completed all three sheets, four were excluded for incomplete data. Total contact rates per 1000 patients listed rose significantly compared with the rates before the change index in the city $(100.0$ before the change $v 111.7$ (95\% confidence interval 106.4 to 117.4 after the change) and over the same time in the control group $(100.0 v 106.0)$, but within a year these rates fell (to $104 \cdot 2(99 \cdot 1$ to $109 \cdot 6$ ) and 104.0 respectively). There was an increase in consultations by telephone initially but not thereafter. Rates of examinations and treatments that attracted specific additional remuneration after the change rose significantly compared with those before (diagnostic services, $138 \cdot 1(118 \cdot 7$ to 160.5$)$ and $159 \cdot 5$ $(137.8$ to 184.7$)$ and curative services 194.6 (152.2 to 248.9) and 194.8 (152.3 to 249.2) for second and third data collections respectively) and with the control group (diagnostic services 105.3, 107.6 and curative services $106.0,115.0$ ) whereas referral rates to secondary care fell (specialist referrals $90 \cdot 1(80 \cdot 7$ to 100.6) and $77.0(68.6$ to 86.4$)$ and hospital referrals $87.4(71 \cdot 1$ to 107.5$)$ and $68.4(54.7$ to 85.4$)$ ) in doctors in the city.

Conclusions-Introducing a partial fee for service system seemed to stimulate the provision of services by general practitioners, resulting in reduced referral rates. The concept of a "target income" which doctors aim at, rather than maximising their income seemed to play a part in adjustment to changing the system of remuneration.

\section{Introduction}

How best to pay doctors, especially general practitioners, has been the subject of considerable debate. Yet as Donaldson and Gerard indicated, "There is little evidence about the effect of different methods of payment on doctors' performance." This study examines the activities of a sample of general practitioners in the city of Copenhagen when they were remunerated on a capitation basis and again in two separate periods after October 1987 when they were paid on a part fee per item basis and part capitation basis. The county of Copenhagen surrounding the city, where the system was partly fee per item and partly capitation throughout, was used as a control.

\section{BACKGROUND}

The Danish health services are primarily a social insurance, tax based, system. All general practitioners have a contract with the public authorities, which provides for care for $95 \%$ of the population ("group l"), who are eligible for all services during weekdays from 8 am to $4 \mathrm{pm}$. Most services, including those provided by general practitioners and hospital care, are free of charge. There are some patient copayments-for example, for medicines, physiotherapy, and dentistry. With the exception of treatment in accident and emergency departments, patients must be referred by their general practitioner if they require hospital care or treatment from specialists who practise outside hospital. On call home services, outside normal working hours, are provided in the city mainly by nongeneral practitioners and in the rest of the country by a doctor who may or may not be a general practitioner. The remaining $5 \%$ of the population have chosen a different system entailing a greater element of copayment, which gives them direct access to any general practitioner or specialist.

The fee for service part of the remuneration system outside the city before October 1987, and in the whole country thereafter, provides fees for face to face consultations, consultations by telephone, home visits, and repeat prescriptions. Additional fees are paid for about 40 special services (for example, cervical smear tests), for about 40 special laboratory investigations performed in the practice (for example, estimation of haemoglobin concentration), and for a few preventive services (for example, immunisations). The fees for preventive services were and are paid to all general practitioners in Denmark independently of those within the general remuneration system.

In the period leading up to October 1987 the general practitioners' incomes in the city fell behind those of their counterparts elsewhere in Denmark, due partly to a general increase in the number of services per person, partly to an increasing proportion of elderly persons, and partly to increasing waiting times for 
admission to hospital and a tendency to discharge hospital inpatients earlier than previously. As these general practitioners were not being compensated for this extra workload whereas those outside the city were, general practitioners in the city desired a change to the remuneration system existing in the rest of Denmark. In agreeing to the change, city authorities wanted general practitioners in the city to undertake fully the duties provided on weekdays from 8 am to $4 \mathrm{pm}$ by on call doctors, as in the rest of the country, and from 1 October 1987 the system in the city was changed accordingly.

\section{HYPOTHESES}

Much has been written about "supplier induced demand" 23 and doctors' behaviour with respect to income and other variables. ${ }^{2+}$ We hypothesised that doctors aim at achieving a "target income" rather than at maximising their income. In this study this target income was assumed to be higher than that being earned before the change because the parties concerned expected that the new agreement would result in general practitioners in the city making up at least some of their lost income compared with general practitioners elsewhere. We further assumed that increases in activity would be greater where the opportunities for supplier inducement were greater.

Three hypotheses emerged from these considerations: (a) general practitioners in the city would increase their overall activity with greater increases, other things being equal, in those activities where they had most discretion; $(b)$ referrals to specialists and hospitals would decrease; $(c)$ in the short term doctors would be more likely to overshoot their target income, thereafter their overall activity falling as they realised that they could attain their target incomes without increasing their workload so much and which services were most financially rewarding.

\section{Subjects and methods}

The study was based on a follow up design with analysis before and after the change in Copenhagen city, with Copenhagen county as the control. In the city 265 general practitioners cater for a population of 470000 and in the county 560000 people are served by 326 general practitioners. Of 140 general practitioners agreeing to take part in the study out of all those in the city who were asked, 10 were excluded because they were tutors of trainees; 100 were selected randomly from the remainder.

Data were collected in three rounds: the first occurred in February/March 1987 (before the change in the remuneration system), the second in February/ March 1988, and the third in November 1988 (both after the change). In each the general practitioners were asked to complete a sheet for each patient contact - both face to face and by telephone-which they had during normal working hours in a particular week. Of the original 100 participants, 86 took part in the second round and 75 completed all three rounds. Of these 75 , four had to be excluded because of incomplete data. Data were collected twice after the change on the assumption that general practitioners would take time to adjust to the new system. On some days because of holidays, illness, absence on courses, etc, a few doctors had no patient contacts. This occurred on $3 \%, 1 \%$, and $2 \%$ of the days studied in the first, second, and third rounds respectively; the data were not adjusted for this. The data sheet elicited information about the age and sex of the patient; the nature of the contact (face to face consultation, telephone consultation, home visit, preventive services, and renewal of prescription); diagnosis; examinations and curative services; and referrals to specialists and to hospital. Only group 1 contacts (excluding preventive services) were used in the analysis. Home visits, accounting for $3 \%$ of the contacts, had to be excluded because no distinction could be drawn between visits to the patient's own home and those to an institution. This left 31947 contacts for the analysis.

Additional data on the age and sex distribution of patients registered with each practice were obtained from the health authorities in Copenhagen city (these data are regularly updated). A comparison of the participating and non-participating doctors by sex and by time since graduation showed that they were similar ( $\mathrm{p}>0.05)$.

As a control, similar data for the same periods as the $\frac{\bar{O}}{\bar{D}}$ three rounds in the city were obtained from the $\vec{\Phi}$ Copenhagen county authorities for all 326 general $\cong$ practitioners. The data were derived from the billing of क fees and from the hospital routine records (referrals). $\overrightarrow{0}$ They were, however, not directly available by indi- $\overrightarrow{\vec{H}}$ vidual practice or doctor but only on a more aggregate $\vec{\omega}$ basis.

The basic measures used to describe changes in doctors' behaviour were the numbers of activities and contacts per week per 1000 enlisted patients.

\section{STATISTICAL METHODS}

The rate of contact of a specific type was defined as $\overrightarrow{\vec{D}}$ the number of contacts per 1000 patients enlisted. The $\underset{\varnothing}{\varnothing}$ data were analysed with a multiplicative Poisson model, in which the relative change in the contact rate for each doctor is the same.

The numbers of contacts for a doctor $\mathrm{d}=1, \ldots, 71$ in $\subseteq$ Copenhagen city at times $t=1$ (March 1987), 2 (March 1988), and 3 (November 1988) were assumed to show $\vec{\theta}$ an independent Poisson distribution with the expecta- $\oslash$ tion:

$$
\mathrm{N}_{\mathrm{dt}} \exp \left\{\alpha_{\mathrm{t}}+\beta_{\mathrm{d}}\right\}
$$

where $\mathrm{N}_{\mathrm{dt}}$ is the number of enlisted persons for doctor $\mathrm{d}$ at time $\mathrm{t}$.

The model hereby adjusted for the number of $\frac{0}{D}$ persons enlisted and differences in the level of activity of the doctors. The changes in rate were then the same $\overrightarrow{0}$ for all doctors. The contact rates in March 1988 and November 1988 compared with those in March 1987 居 were $\exp \left\{\alpha_{2}-\alpha_{1}\right\}$ and $\exp \left\{\alpha_{3}-\alpha_{1}\right\}$ respectively.

For the three types of contacts (face to face consultations, consultations by telephone, and renewal of prescriptions) the changes in contact rates did not depend on the doctors' age or sex nor on the number of persons enlisted nor their age or sex distribution, at $\delta$ March 1987. Maximum likelihood methods were used $₹$ to obtain estimates and their standard errors. In the 윽 event that the data showed larger dispersion than the $N$ Poisson variation, the standard errors were increased. ${ }^{S}$ G The estimated relative changes in contact rate in Copenhagen city were compared with the development in the number of contacts per 1000 patients enlisted 0 in Copenhagen county. In a similar way the number $\omega$ of diagnostic activities, treatments, and referrals to specialists and hospitals were analysed.

\section{Results}

Table I shows the actual numbers of contacts and $\frac{\vec{D}}{\vec{D}}$

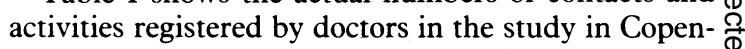

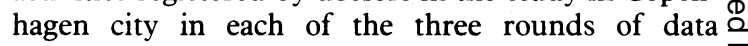
collection. Of the total 31947 contacts, $19807(62 \%)$ 을 were face to face consultations, $9904(31 \%)$ consul- 8 tations by telephone and $2236(7 \%)$ entailed only을 renewing a prescription. Table II shows the estimated changes in rates of these activities in the city and the county. Total contacts rose in the city and significantly between the first and second rounds of data collection. The increase was significantly greater than in the county over the same period. In the third round of the 
survey in the city, however, there was no significant difference compared with before the change, nor was there any significant difference compared with the change in the county. A similar pattern occurred for the rate of face to face consultations. For consultations by telephone, however, the increase remained significant at the third round, compared with the rates in the city in the first round and in the county at the third round. The rate of renewal of prescriptions showed a significant fall from the first to the second round but not compared with that in the county over the same period. The fall in the third round was even greater and by that time significantly different from the fall in the county. The data for contacts disaggregated by type of diagnosis (infectious versus non-infectious) showed similar patterns to the aggregate data (not shown).

Table III differentiates activities by examinations, curative services, referrals to specialists, and referrals to hospital in the city and in the county. In the city significant increases were found in the rate of examinations and curative services between both the first and second rounds and the first and third rounds, which were significantly larger than the increases in the rates in the county. The rates of referrals to hospital and to specialists decreased significantly and the decreases in the rates were significantly different only from those in the county at the third round.

\section{Discussion}

The element of self selection inherent in the selection of the 71 doctors included in the analysis means that they might not be typical in terms of their responses. At least for sex and years since graduation, however, there were no significant differences between the participating and non-participating doctors. The nature of any bias introduced by the method of selecting the sample is difficult to predict. An earlier

TABLE I-Number of contacts and activities in a week and number of enlisted patients in March 1987, March 1988, and November 1988 for 71 doctors in Copenhagen city

\begin{tabular}{|c|c|c|c|}
\hline & $\begin{array}{c}\text { March } \\
1987\end{array}$ & $\begin{array}{c}\text { March } \\
1988\end{array}$ & $\begin{array}{c}\text { November } \\
1988\end{array}$ \\
\hline Contacts & 9942 & 11387 & 10618 \\
\hline Diagnostic services` & 536 & 768 & 896 \\
\hline Curative services ${ }^{\star}$ & 99 & 201 & 203 \\
\hline Referrals to specialist & 1276 & 1176 & 1002 \\
\hline Referrals to hospital & 251 & 226 & 176 \\
\hline Number of enlisted patients & 122223 & 125412 & 125536 \\
\hline
\end{tabular}

$\star$ Services for which additional fee is paid.

TABLE II - Estimated changes in number of contacts per 1000 enlisted patients in March and November 1988 compared with that in March 1987 in Copenhagen city (95\% confidence interval) and change in Copenhagen county, by type of contact

\begin{tabular}{|c|c|c|c|c|c|}
\hline \multirow[b]{2}{*}{ Type of contact } & \multirow[b]{2}{*}{$\begin{array}{c}\text { March } \\
1987\end{array}$} & \multicolumn{2}{|c|}{ Copenhagen city } & \multicolumn{2}{|c|}{ Copenhagen county } \\
\hline & & $\begin{array}{c}\text { March } \\
1988\end{array}$ & $\begin{array}{c}\text { November } \\
1988\end{array}$ & $\begin{array}{c}\text { March } \\
1988\end{array}$ & $\begin{array}{c}\text { November } \\
1988\end{array}$ \\
\hline Face to face consultations & 100 & $112.7(106.8$ to 118.8$)$ & $104.4(98.9$ to 110.2$)$ & $105 \cdot 5$ & $104 \cdot 9$ \\
\hline Consultations by telephone & 100 & $118.6(108.5$ to $129 \cdot 7)$ & $115 \cdot 4(105 \cdot 5$ to $126 \cdot 3)$ & $108 \cdot 4$ & $104 \cdot 0$ \\
\hline Renewal of prescriptions & 100 & $82.5(68.4$ to $99 \cdot 7)$ & $65 \cdot 2(53 \cdot 2$ to $79 \cdot 9)$ & $91 \cdot 5$ & $92 \cdot 6$ \\
\hline Total & 100 & $111.7(106.4$ to $117 \cdot 4)$ & $104 \cdot 2(99 \cdot 1$ to $109 \cdot 6)$ & $106 \cdot 0$ & $104 \cdot 0$ \\
\hline
\end{tabular}

TABLE III - Estimated changes in number of activities per 1000 enlisted patients in March and November 1988 compared with that in March 1987 in Copenhagen city (95\% confidence interval) and change in Copenhagen county, by type of activity

\begin{tabular}{lcccrrr}
\hline & & \multicolumn{2}{c}{ Copenhagen city } & \multicolumn{2}{c}{ Copenhagen county } \\
\cline { 3 - 4 } \cline { 6 - 7 } & March & March & November & & March & November \\
Type of activity & 1987 & 1988 & 1988 & & 1988 & 1988 \\
\hline Diagnostic services & 100 & $138 \cdot 1(118 \cdot 7$ to $160 \cdot 5)$ & $159 \cdot 5(137 \cdot 8$ to $184 \cdot 7)$ & & $105 \cdot 3$ & $107 \cdot 6$ \\
Curative services & 100 & $194 \cdot 6(152 \cdot 2$ to $248 \cdot 9)$ & $194 \cdot 8(152 \cdot 3$ to $249 \cdot 2)$ & & $106 \cdot 0$ & $115 \cdot 0$ \\
Referrals to specialist & 100 & $90 \cdot 1(80 \cdot 7$ to $100 \cdot 6)$ & $77 \cdot 0(68 \cdot 6$ to $86 \cdot 4)$ & & $99 \cdot 4$ & $98 \cdot 1$ \\
Referrals to hospital & 100 & $87 \cdot 4(71 \cdot 1$ to $107 \cdot 5)$ & $68 \cdot 4(54 \cdot 7$ to $85 \cdot 4)$ & & $97 \cdot 1$ & $102 \cdot 1$ \\
\hline
\end{tabular}

study of general practitioners in Copenhagen county showed that, compared with doctors participating in research entailing contact registration, those not participating had a less positive attitude towards a holistic model of disease but were more positive towards general practice as a form of free enterprise. ${ }^{6}$ This supports the proposition that non-participating doctors in our study would be more sensitive to financial incentives than the participants and that, consequently, our results may underestimate any change. In the control area (Copenhagen county) all general practitioners practising at the times when the data were collected in the city were included; thus no selection occurred.

Though the populations of the city and the county differ in their demographic and health characteristics (for example, there being more single people and a generally lower state of health in the inner city), together they comprise the sociogeographically defined capital and are influenced by the same general social and environmental factors. Seasonal variations in contact rates and epidemics of infectious diseases are also expected to be similar in the city and the county. Given the design of the study we believe that the county is a very appropriate control.

The data for the city collected from special sheets completed by the general practitioners may be subject to underreporting, and this might have increased during the study. Doctors might have tired of filling in the forms, and after the change in the remuneration system there was a greater component of direct cost to the doctor in spending time completing the sheets. The results in the city may thereby underestimate the true activity of doctors at the second and third rounds of data collection.

In terms of our first hypothesis - that activity would increase overall but most in those areas where doctors had most discretion-activity indeed increased after the change. The impact was, however, more in terms of adding on services to patients consulting their doctor than in adding on patients, when the doctor probably has less discretion.

In support of our second hypothesis - that referrals would decrease-our data showed that the general practitioners seemed to have taken the opportunity to undertake some services previously provided by the hospitals and specialists. Our third hypothesis - that of the concept of a target income higher than that previously achieved before the change-is supported by our results. Other explanations are, however, possible to account for the tendency for the level of activity to fall between the second and third rounds of the data collection after the initial increase between the first and the second rounds. For example, general practitioners may simply take time to learn about their own preferences for income and leisure under the new remuneration arrangements, and this is an important consideration; we have no knowledge of or evidence on the appropriate learning periods.

One other important result is the substantial fall in renewals of prescriptions; this may be partly explained by some redefinition by the general practitioners of their activities because under the new scheme consultations attract higher remuneration than renewal of a prescription.

What we could not sort out separately was any effect the formal change in hours may have had on the change in general practitioners' activities. As a result of the change doctors would have become more accessible to their patients. We would have expected the effect to show in those variables which are sensitive to greater access, presumably patient contacts rather than services per patient. As the change in the patient contacts was in any case small it supports the view that the influence of the change in hours is small. 
In comparing our results with those of earlier studies one major difficulty is the general paucity of research,? another is that many earlier studies had design weaknesses: they are cross sectional and compare different organisational structures, not just remuneration systems ${ }^{8}$; or they compare across different patient or general practitioner groups. ${ }^{9}$ Some evidence is, however, available to support the idea of a target income,${ }^{10}$ which we adopted, with modification, in this study. Donaldson and Gerard suggested that "guaranteed [capitation] payment may encourage some general practitioners to cut their financial and personal costs by curtailing consultation time, by excessive prescribing, or by overreferral to hospitals." Our evidence supports the direction of such shifts, at least for referrals.

Our study throws light on the presence and, to a limited extent, the nature of supplier inducement. Research is now required on what constitutes "optimal inducement." Our results also highlight the possibilities for altering the balance of care between different health care sectors-for example, between general practitioner and hospital. It does not, nor was it intended to, indicate what is optimal.

1 Donaldson C, Gerard K. Paying general practitioners: shedding light on the review of health services. I $R$ Coll Gen Pract 1989;39:114-7.

2 Evans RG. Supplier-induced demand: some empirical evidence and implications. In: Perlman M, ed. The economics of health and medical care. New York: Wiley, 1974:162-73.

3 Evans RG. Strained mercy: the economics of Canadian health care. Toronto: Butterworth, 1984.

4 Richardson J. The inducement hypothesis: that doctors generate demand for their own services. In: van der Gaag J, Perlman M, eds. Health, economics and health economics. Amsterdam: North Holland, 1981:189-214.

5 McCullagh P, Nelder JA. Generalized linear models. London and New York: Chapman and Hall, 1983:133.

6 Gannik D, Frimodt-Møller B, Heldrup J, Hollnagel H, Pedersen PA. Diagnosis and treatment in general practice. 6. Attitudes of general Diagnosis and treatment in general practice. 6 . Attitudes of general
practitioners. A study in Copenhagen county. Ugeskr Laeger 1989;151: practition $165-72$.

7 Richardson J. Payment methods for ambulatory care. Melbourne: Public Sector Management Institute, Monash University, 1989. (Discussion paper.)

8 Rosen B. Professional reimbursement and professional behaviour: emerging issues and research challenges. Soc Sci Med 1989;29:455-62.

9 Rutten FFH, van der Gaag J. Referrals and demand for specialist care in the Netherlands. Health Serv Res 1977;12:233-49.

10 Rice TH. The impact of changing medicare reimbursement rates on physicianinduced demand. Med Care 1983;21:803-15.

(Accepted l May 1990)

\section{MATERIA NON MEDICA}

\section{Dunkirk 1990}

I was fortunate enough to find myself by chance taking part in the 50th anniversary of the evacuation of Dunkirk.

We had chosen to use the bank holiday weekend to cross the Channel, intending to spend two days in France and Belgium. A friend of ours, John, had helped to organise a flotilla of small sailing dinghies (with suitable motorised escort), which had sailed from Dover on Saturday morning. Unfortunately, the crossing had been quite rough and after a long day of beating against the wind they had put in at Calais instead of Dunkirk. We were therefore able to meet them in the yacht basin at Calais on Sunday.

Six of us then set off by car to Dunkirk. Strangely, there was little in the way of signposting for the casual visitor, but we made our way through the deserted dockyard and found

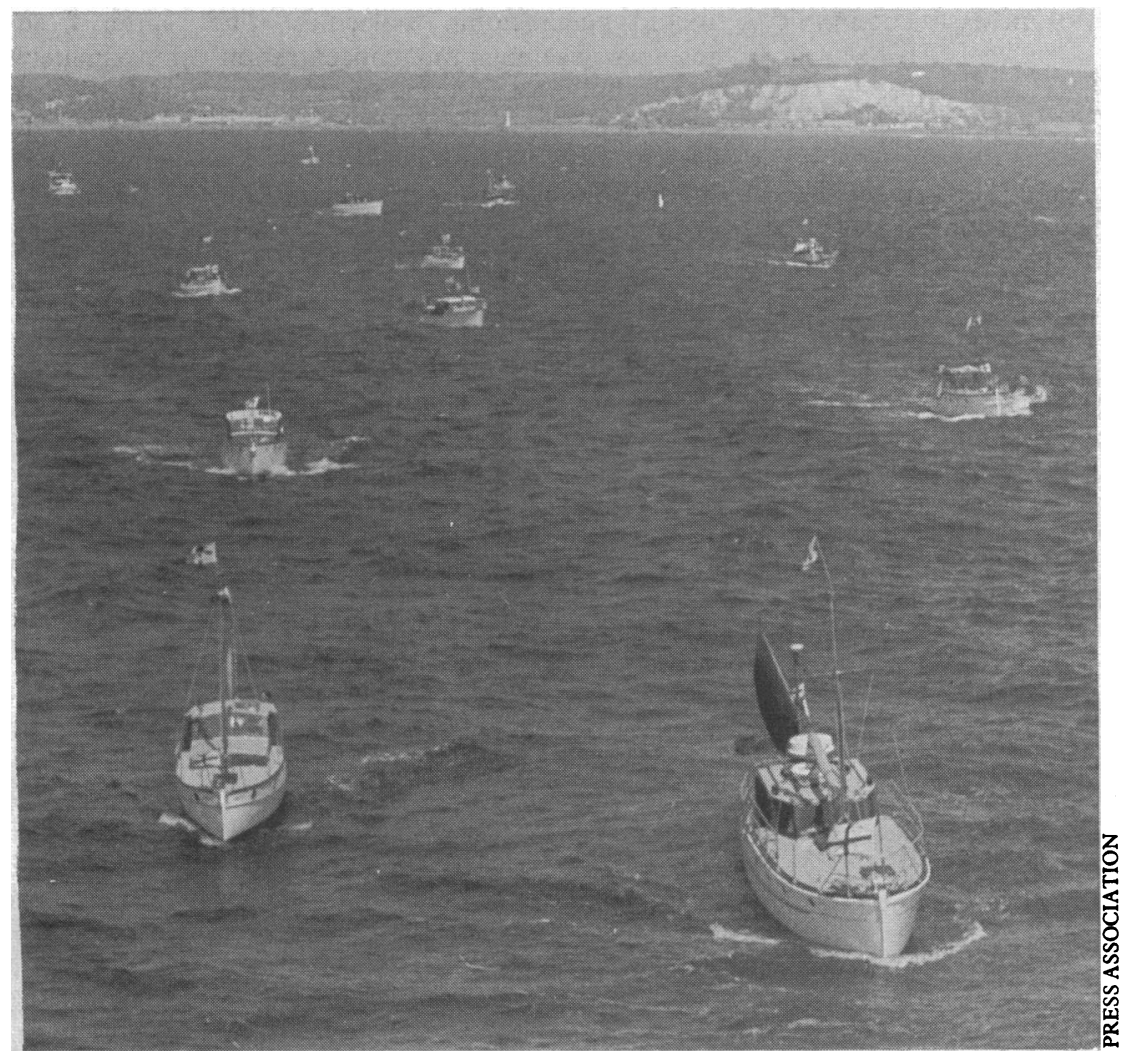

ourselves on the end of one of the entrances to the inner harbour, with direct views both to the outer harbour and across to the town beach.

It was a very moving experience. There was little noise to be heard from where we were standing, but we could see the many people ranged along the sandy beach. Out in the bay was a memorable sight. Slowly circling around two large grey navy frigates was a proud parade of "little ships" of all shapes and sizes. In particular we could identify the paddle steamer Waverley, the three Thames barges, and the fire boat.

The sky was clear and blue and the sea barely troubled by a light south easterly breeze. A helicopter flew over, hovered low, and dropped a wreath. Then came the fly past of a Lancaster bomber flanked by a Spitfire and a Hurricane. How tiny the fighters looked, and how strange to hear the double thrum of the bomber's engines, familiar to my generation only from war films and newsreel. Finally the Red Arrows flew over in a single sweep of tribute.

As the small boats then began to peel off from their circle and approach the outer harbour, all was warmth and tranquillity. It was impossible to imagine the hell which they had entered as they approached Dunkirk 50 years ago.

The following morning we took up John's offer of a ride back across the Channel with the flotilla. There were 20 dinghies in all, most of them Wayfarers (about $16 \mathrm{ft}(5 \mathrm{~m})$ ). I was in a Moore's Broads dinghy - slightly larger and with a small motor for emergency use. There were two large rubber Humbers and a wooden rescue boat, a big diesel cruiser, and a couple of smaller motor boats as escorts.

The Channel is extremely busy, and crossing in a flotilla of sailing boats felt a bit like trying to cross the $M 1$ with a brood of ducklings. During the late afternoon the wind swung round to the south and by $7 \mathrm{pm}$ had died completely. Our commodore in a Humber began busily chasing up stragglers and organising towing groups so that we could clear the shipping lanes and also get to Dover before dark. So we motored the final part of our crossing and finally scurried in to reach the safety of the area inside the yellow buoys just at dusk.

It was not quite what we had planned for our weekend break, but I am delighted to have had the experience. When my future grandchildren are studying the second world war for their history GCSE not only will I have their great grandfather's photographs to show them but also their grandmother's photographs of the 50th anniversary tribute to the unselfish valour of the "little ships" and her own small participation in that tribute. It was a privilege to be there.-KATHERINE M BRADNOCK, general practice trainee, Buckinghamshire 